\title{
Immediate Effects of the Arizona Alcohol Warning Poster
}

\author{
Andrea M. Fenaughty and David P. MacKinnon
}

\begin{abstract}
Exposure to, awareness of, beliefs about, and memory for the warning on the recently required Arizona alcohol warning poster were measured in a sample of college students before $(\mathrm{N}=362)$ and after $(\mathrm{N}=332)$ the legislation became effective on January $1,1992$. The introduction of the warning poster was associated with greater exposure, awareness, and memory. The authors found inconsistent evidence for an association between the introduction of the warning poster and beliefs. Secular trends did not appear to be responsible for these changes.
\end{abstract}

$\mathbf{F}$ etal alcohol syndrome (FAS), a pattern of malformations found in children whose mothers drank alcohol excessively during pregnancy, includes mental retardation, reduced birth weight and length, and microcephaly [Jones and Smith 1976; Jones et al. 1973; Rosett, Ouellette, and Weiner 1976]. The term "fetal alcohol effect" (FAE) denotes less pronounced symptomatology when only a few of the criteria for FAS are met [U.S. Department of Health and Human Services 1990].

Available estimates suggest a rate of 2.6 FAS births per 1000 live births for black and American Indian mothers of low socioeconomic status and .6 FAS births per 1000 live births for white middle class mothers [U.S. Department of Health and Human Services 1990]. The prevalence of FAE is estimated to be even higher. The cost of caring for FAS babies is estimated to be nearly a third of a billion dollars annually in the United States alone [U.S. Department of Health and Human Services 1990]. The estimated cost of caring for all of the FAS children born in Arizona during 1989 may be as high as $\$ 160$ million over their lifetimes [Roth 1991].

\section{Prevention of Pregnant Women's Alcohol Consumption}

Fetal alcohol syndrome now outranks Down's syndrome and spina bifida as the leading cause of mental retardation in the United States [Abel and Sokol 1986]. Because FAS is the only one of these causes that is preventable, programs to reduce its occurrence have received high priority [Warren and Bast 1988]. Treatment programs have been developed to reduce alcohol consumption among pregnant women [Halmeski 1988; Rosett, Weiner, and Edelin 1983]. Other programs have been designed to increase knowledge and awareness among health providers so that they can iden-

Andrea M. Fenaughty is a doctoral candidate and David P. MacKInnon is Assistant Professor Department of Psychology, Arizona State University. The research was supported in part by a Public Health Service grant (AA8547) to Dr. MacKinnon (Principal Investigator) from the National Institute on Alcohol Abuse and Alcoholism. Parts of this article were presented at the 1992 Western Psychological Association Conference, Portland, OR. The authors thank the anonymous JPP\&M reviewers for several helpful comments. tify women at risk of having FAS and FAE babies [Little et al. 1983; Russell, Kang, and Uhteg 1983].

The objective of a third type of prevention activity is to increase the general public's awareness of the risks of a pregnant woman's alcohol consumption [MacKinnon et al. 1991; May et al. 1983; Waterson and Murray-Lyon 1990]. The rationale of this approach is that (1) FAS awareness should occur before pregnancy because alcohol consumption is problematic even in the earliest stages of pregnancy and (2) the maximum number of people should be exposed to FAS information so that an informed general public will disseminate this awareness to the pregnant women who may actually engage in the alcohol consumption that places the fetus at risk. Two major legislative strategies that have been enacted to increase public awareness of FAS are warning labels on containers of alcohol and warning posters in establishments that sell alcohol.

\section{Alcohol Warning Labels}

Warning labels have been required on all alcohol beverage containers since November 18, 1989. The fetal risk associated with pregnant women's alcohol consumption is one of the most prominent warnings on the label. The risk message was written to inform and remind the public about the risks of alcohol use and to reduce uncertainty and misperceptions about alcohol use consequences. The content of the warning label is: "GOVERNMENT WARNING: (1) According to the Surgeon General, women should not drink alcoholic beverages during pregnancy because of the risk of birth defects. (2) Consumption of alcoholic beverages impairs your ability to drive a car or operate machinery, and may cause health problems"' [H.R. 5409, 1988; H.R. 5210, 1988].

Though evaluations are not yet complete, there is already some positive evidence about the effects of the alcohol warning label. Hilton [1991] found that $27.5 \%$ of respondents to a phone survey were aware of the label after it appeared, whereas $7.8 \%$ reported being aware of the label before it actually appeared. Mazis, Morris, and Swasy [1990] also reported gains in awareness of the warning label and greater increases in awareness among heavier drinkers and younger people. Kaskutas and Greenfield [1991] similarly found larger increases in alcohol warning label awareness among the heaviest drinkers in their sample. MacKinnon, Pentz, 
and Stacy [1993] found substantial changes in exposure to, awareness of, and memory for the warning label, but only negligible changes in perceived harmfulness of alcohol use. A multiple-wave study by Scammon, Mayer, and Smith [1991] compared devout Mormon (nondrinkers) with nonMormon (drinkers) residents of Utah on measures of awareness and warning-label-relevant risk perception before and after the alcohol warning label legislation became effective. Results indicated that warning labels were noticed more after they had appeared, but no change was found in the perception of risk associated with alcohol consumption.

\section{Alcohol Warning Posters}

The second legislative strategy to increase public awareness of FAS, warning posters, has not received much research attention. Beginning in 1983, New York City required posters warning about the risks associated with drinking while pregnant. Georgia, South Dakota, and California mandated that, starting in 1986, such warnings appear in all establishments in their states where alcoholic beverages are sold. These posters primarily warn of the fetal injury associated with a pregnant woman's alcohol consumption, though other risks also are mentioned (e.g., the risk of cancer is mentioned on the California poster). The Arizona alcohol warning poster legislation, which targets both the general public and pregnant women in particular, requires a poster describing solely the risk of fetal injury. The Center for Science in the Public Interest now identifies nine states and 17 cities that require such posters [Hayes 1991].

Apparently only one study has been done on the effects of these posters. In that study of the New York City warning poster, $54 \%$ of the persons interviewed before the warning poster appeared mentioned birth defects as a possible consequence of a pregnant woman's alcohol consumption. A year later, after the poster had appeared, $68 \%$ mentioned birth defects [Prugh 1989]. The results of this study suggest that warning posters are capable of increasing awareness of the possible consequences of a pregnant woman's alcohol consumption.

The focus of our research is the Arizona alcohol warning poster legislation. The following warning message was required to appear in all establishments that sell alcoholic beverages as of January 1, 1992: "WARNING: DRINKING DISTILLED SPIRITS, BEER, COOLERS, WINE, AND OTHER ALCOHOLIC BEVERAGES DURING PREGNANCY CAN CAUSE BIRTH DEFECTS' [Arizona Revised Statutes § 4-261, 1991]. Failure to comply with the state law after March 1992 may result in suspension and revocation of the license to sell alcohol or in refusal to renew a license. ${ }^{1}$ Our study was designed to assess the effect of this legislation on college students' exposure to and awareness of the poster, beliefs about the risk of drinking alcohol while pregnant, and memory for the warning.

\section{Study Method}

\section{Subjects}

Subjects were 694 Arizona State University undergraduate students who participated in the research in partial fulfill-
Table 1. Sample Description Before and After Warning Poster Legislation, Including Demographic and Other Covariates

\begin{tabular}{lcc} 
Variable & Before (\%) & After (\%) \\
$\begin{array}{l}\text { Female gender } \\
\text { Age in years (mean) }\end{array}$ & 49.4 & 52.0 \\
$\begin{array}{l}\text { White } \\
\begin{array}{l}\text { Drank at least one } \\
\text { alcoholic drink last month }\end{array}\end{array}$ & 20.5 & 20.3 \\
$\begin{array}{l}\text { Worked past year in an } \\
\text { establishment that sells } \\
\text { alcohol }\end{array}$ & 81.4 & 76.7 \\
$\begin{array}{l}\text { Lived last year in a state } \\
\text { that had an alcohol warning } \\
\text { poster }\end{array}$ & 11.3 & 77.4 \\
$\begin{array}{l}\text { Saw the alcohol } \\
\text { warning label }\end{array}$ & 11.6 & 9.9 \\
$\begin{array}{l}\text { Knew the label } \\
\text { exists }\end{array}$ & 57.6 & 12.1 \\
$\begin{array}{l}\text { Knew the law for } \\
\text { the label exists }\end{array}$ & 63.0 \\
\hline $\begin{array}{l}\text { a } \\
\text { ahe exposurc to the alcohol warning label measure described in the text is an index } \\
\text { of these three items (coefficient alpha=.88). }\end{array}$ & 63.4 \\
\hline
\end{tabular}

ment of a psychology course requirement. Three hundred sixty-two subjects completed a questionnaire in the fall of 1991, before the Arizona warning poster was required to appear; 332 completed the questionnaire in the spring of 1992, after the warning poster was required to appear. College student samples have been used in previous studies of the alcohol warning label [Andrews, Netemeyer, and Durvasula 1990]. Issues of external validity are discussed in more detail in the Discussion section.

As shown in Table 1, the fall sample was $49.4 \%$ female, had a mean age of 20.5 years, and was $81.4 \%$ white. The spring sample was $52.0 \%$ female, had a mean age of 20.3 years, and was $76.7 \%$ white. The proportion of subjects who had consumed at least one alcoholic drink in the last month was $74.0 \%$ and $77.4 \%$ for the fall and spring samples, respectively.

\section{Design}

Because natural exposure to the warning poster was not under experimental control, randomization of subjects to different levels of exposure to the poster was not possible. In such a nonexperimental design, comparisons were needed to address alternative explanations for observed changes [Cook and Campbell 1979]. We evaluated the effect of the alcohol warning poster by examining pre- and post-legislation measures that should be affected by an alcohol warning poster, adjusting for possible confounding variables, including measures that are similar to the alcohol dependent measures but should not be affected by the poster.

Because different subjects were measured before and after the legislation, an alternative explanation of changes in the dependent measures is that the sample taken after the 
legislation is different from the sample taken before the legislation. Measures of gender, age, race, alcohol use, exposure to the poster through employment at an establishment that sells alcohol, and having lived in a state (in the past year) that has an alcohol warning poster were used to equate the samples taken before and after the legislation. Because increases in awareness of the risk of drinking while pregnant may be due to alcohol container label legislation, exposure to the alcohol warning label was also included as a covariate.

One additional set of covariates, cigarette measures that correspond to the alcohol dependent measures, were also included. For example, we asked respondents whether they had seen a poster warning of the harmful effects of maternal cigarette smoking on the fetus (a poster that does not exist in Arizona) and whether they were aware of the risk of smoking cigarettes while pregnant. The paired cigarette and alcohol measures were positively correlated. For example, people who believed that cigarettes are harmful during pregnancy were likely to believe that alcohol is harmful during pregnancy. If there is a general trend in beliefs about the effects of mother's drug use on the fetus and awareness of posters, a variable that codes the appearance of the alcohol warning poster (hereinafter called the law variable) will not account for significant variance in the alcohol dependent measure when we control for the corresponding cigarette measure. If the alcohol warning poster is responsible for increases in exposure, awareness, beliefs, and memory, the law variable should account for significant variance in the alcohol measure above and beyond the variance accounted for by the corresponding cigarette measure.

\section{Measures}

As shown in the Appendix, the following constructs were measured for both alcohol and cigarettes: exposure to the warning poster, awareness of the warning poster and the law requiring it, beliefs about the risk to the fetus of maternal alcohol consumption (and cigarette smoking), and beliefs about the benefits of avoiding alcohol (and cigarettes) if pregnant. Free recall and recognition memory for the message on the alcohol warning poster also were measured. The alcohol measures were used as dependent variables, the corresponding cigarette measures were used as covariates. The scale used for the exposure, awareness, and the first beliefs measures was: 1 (no), 2 (no, I don't think so), 3 (yes, probably), 4 (yes, definitely). The Likert-type scale used to measure beliefs about the benefits of avoiding alcohol (and cigarettes) ranged from 1 (not at all beneficial) to 6 (extremely beneficial). Both free recall and recognition memory were scored as either correct (1) or incorrect ( 0 ). Half of the subjects randomly received the free-recall memory test, for which a response describing the FAS/birth defects risk of alcohol use during pregnancy (and no mention of any other risk) was coded 1 and any other response (or lack of a response) was coded 0 . The other half of the subjects randomly received a forced choice recognition test, for which the correct response was coded 1 , and the incorrect distractor response and the "I don't know" response were coded 0 . The distractor warning on the recognition test was identical to the alcohol warning label. For all measures, higher numbers indicate positive effects of the warning poster (i.e., more exposure and awareness, more accurate beliefs, better memory).

The primary independent variable was whether the student completed the questionnaire before $(0)$ or after (1) the warning poster law went into effect (law variable). Additional predictor variables were male (1) or female (0), age (in years), white (1) or nonwhite (0), alcohol use in the last month (no use to heavy use), employment in an establishment where alcohol is sold (1) or not $(0)$, having lived the past year in a state that had an alcohol warning poster (1) or not (0), and previous exposure to the alcohol warning label. The warning label exposure variable is an index created by taking the mean of three standardized items: (1) having seen the alcohol warning label, (2) being aware of the alcohol warning label, and (3) being aware of the law requiring the alcohol warning label. These three warning label items were measured on the 1 to 4 scale described previously, with higher numbers indicating greater warning label exposure in each case. Coefficient alpha for this index is .88, indicating acceptable reliability.

\section{Procedure}

Subjects arrived at a designated room in groups of 10 to 20 and were seated at separate desks. Each subject received a questionnaire and was instructed to complete it without talking to other subjects. Once finished (approximately $15 \mathrm{~min}$ utes), each subject turned in his or her completed questionnaire and was thanked for participating in the study.

\section{Data Analysis}

Analysis of covariance (ANCOVA) was used to estimate the relationship between the introduction of the alcohol warning poster (i.e., law) and changes in the alcohol measures, with adjustment for the following covariates: gender, age, race, alcohol use, the exposure variables ${ }^{2}$, and the corresponding cigarette measure. For example, in the analysis of each alcohol dependent variable (e.g., awareness of the alcohol warning poster), the matching cigarette measure (e.g., awareness of the cigarette warning poster) was included in the ANCOVA. We predicted that the law variable would account for significant variance in each of the dependent measures, even when all covariates were included.

The analyses were repeated with difference scores as the dependent variable. The difference scores were created by subtracting each cigarette covariate from its corresponding alcohol dependent variable. Ordinal logistic regression analyses were also conducted to establish that the same conclusions were obtained under the assumptions of ordinal and interval-level data. The ordinal logistic model assumes that differences between response options are ordinal rather than interval as assumed in ordinary regression models [Muthen 1987; Muthen and Kaplan 1985]. These analyses led to conclusions identical to those of the ANCOVA analyses.

An additional analysis was conducted to test for the presence of a law by alcohol use interaction effect on the awareness dependent measure. Previous research has demonstrated an interaction such that after the alcohol warning label appeared, heavy users of alcohol had a greater increase in awareness of the label than did light users of alco- 
hol [Kaskutas and Greenfield 1991; MacKinnon, Pentz, and Stacy 1993; Mazis, Morris, and Swasy 1990]. The interaction term was created from the product of centered alcohol use and warning poster introduction variables. Warning poster introduction, alcohol use, and the interaction term were then included in the ANCOVA.

\section{Test for Parallel Slopes}

One of the assumptions underlying analysis of covariance is homogeneity of regression slopes. This assumption means that for ANCOVA results to be interpretable, the relationship between the covariate(s) and the dependent variable should be the same at all values of the independent variable. Hence, we should be able to demonstrate the same relationship between each covariate and the dependent variable with the wave 1 pre-warning-poster sample as with the wave 2 post-warning-poster sample.

The appropriate model for testing and adjusting for heterogeneity of regression slopes is one that contains the interaction terms of each covariate by the independent variable [Huitema 1980]. These models are created by first centering each variable in the model, then including both the main effect and interaction terms in the model. A significant interaction term indicates heterogeneity of regression slopes. We tested for homogeneity of regression slopes for the three most consistently significant covariates in our study-each corresponding cigarette measure, work exposure, and warning label exposure.

\section{Results}

\section{Descriptive Analysis}

Table 2 gives the means (unadjusted and adjusted for all covariates $^{3}$ ) for the dependent variables before and after the $\mathrm{Ar}$ izona alcohol warning poster was required to appear. Exposure, awareness, beliefs, and memory for the alcohol warning poster increased after the warning poster law was enacted.

\section{Analysis of Covariance}

Table 3 reports the standardized betas for the law variable and each covariate across all six dependent variables. We discuss these results according to each of the dependent variables: exposure, awareness, beliefs, and memory. All reported $p$-values are two-tailed.

\section{Poster Exposure}

The law variable accounts for variance in subjects' reports of having seen the poster $(\beta=.15, p<.001)$. Exposure to the cigarette poster also accounts for significant variance $(\beta$ $=.35, p<.001)$. Gender is marginally significant $(\beta=-.07$, $p<.10$ ); women reported more exposure. Age accounts for significant variance in this dependent measure $(\beta=.13, p<$ $.001)$. Exposure to the poster at work $(\beta=.15, p<.001)$ and exposure to the alcohol warning label $(\beta=.09, p<.05)$ account for significant variance in exposure to the alcohol warning poster.

\section{Table 2. Unadjusted (and Adjusted ${ }^{2}$ ) Means for Exposure, Awareness, Beliefs, and Memory Before and After the Warning Poster Law}

\begin{tabular}{l|ll|}
\hline Item & Before & After \\
$\begin{array}{l}\text { Exposure } \\
\text { Have you seen the alcohol } \\
\text { warning poster? }\end{array}$ & $2.02(1.81)$ & $2.43(2.12)$
\end{tabular}

Poster Awareness

Is there an alcohol warning poster?

$2.27(1.83)$

$2.59(2.08)$

Law Awareness

Is there a law requiring

alcohol warning posters?

$2.17(1.67) \quad 2.38(1.87)$

Beliefs 1

Can drinking alcohol during

pregnancy cause birth defects?

$3.75(3.21) \quad 3.84(3.30)$

Beliefs 2

How beneficial is it to avoid

drinking if pregnant?

$5.85(1.71) \quad 5.85(1.72)$

\section{Memory}

Accurate recall for warning

Accurate recognition of the warning

$.17(.28)$

$.30(.43)$

$.18(.22) \quad .30(.33)$

Means adjusted for gender, age, race, alcohol use, the exposure variables (work,
warning label, state with a poster), and the cigarette measure are in parentheses.

\section{Poster Awareness}

The introduction of the alcohol warning poster accounts for significant variance in awareness of the Arizona alcohol warning poster $(\beta=.14, p<.001)$, as does awareness of a cigarette warning poster $(\beta=.35, p<.001)$. Of the demographic variables, gender $(\beta=-.07, p<.10)$ and age $(\beta=$ $.08, p<.05$ ) account for some of the poster awareness variance; women and older subjects were more aware of the alcohol warning poster. Other significant covariates are exposure to the warning poster at work $(\beta=.12, p<.001)$ and exposure to the alcohol warning label $(\beta=.13, p<.001)$.

\section{Law Awareness}

The law variable similarly accounts for significant variance in awareness of the law requiring the Arizona alcohol warning poster $(\beta=.12, p<.001)$. Awareness of a law requiring an Arizona cigarette warning poster accounts for significant variance in this dependent variable as well $(\beta=.42, p<$ $.001)$. Age accounts for marginal variance in law awareness $(\beta=.06, p<.10)$. Work exposure to the warning poster $(\beta$ $=.16, p<.001)$ and exposure to the warning label $(\beta=.12$, $p<.001)$ also accounts for significant variance in warning poster law awareness.

\section{Beliefs I}

The introduction of the poster accounts for significant variance in the belief that maternal consumption of alcohol can lead to birth defects $(\beta=.11, p<.01)$, as does the belief 
Table 3. Standardized ANCOVA Estimates for Law and Significant Covariates

\begin{tabular}{|c|c|c|c|c|c|c|c|c|c|}
\hline $\begin{array}{l}\text { Dependent } \\
\text { Variables }\end{array}$ & Law & Cig $^{\mathbf{a}}$ & Gender & Age & Race & $\begin{array}{c}\text { Alcohol } \\
\text { Use }\end{array}$ & $\begin{array}{c}\text { Work } \\
\text { Exposure }\end{array}$ & $\begin{array}{c}\text { Label } \\
\text { Exposure }\end{array}$ & $\begin{array}{c}\text { Poster } \\
\text { State }\end{array}$ \\
\hline $\begin{array}{l}\text { Poster } \\
\text { exposure }\end{array}$ & $.15^{* * *}$ & $.35 * * *$ & $-.07+$ & $.13 * * *$ & .05 & .05 & $.15^{* * *}$ & $.09 *$ & .03 \\
\hline $\begin{array}{l}\text { Poster } \\
\text { awareness }\end{array}$ & $.14 * * *$ & $.35 * * *$ & $-.07+$ & $.08 *$ & .04 & .05 & $.12^{* * *}$ & $.13^{* * *}$ & .00 \\
\hline $\begin{array}{l}\text { Law } \\
\text { awareness }\end{array}$ & $.12 * * *$ & $.42 * * *$ & -.03 & $.06+$ & .04 & .00 & $.16^{* * *}$ & $.12 * * *$ & .04 \\
\hline $\begin{array}{l}\text { Birth } \\
\text { defects } \\
\text { beliefs }\end{array}$ & $.11 * *$ & $.17 * * *$ & $-.15^{* * *}$ & -.05 & .03 & .00 & .01 & $.07+$ & .05 \\
\hline $\begin{array}{l}\text { Benefits } \\
\text { beliefs }\end{array}$ & .01 & $.74^{* * *}$ & -.02 & -.04 & .02 & -.00 & -.04 & .02 & -.00 \\
\hline Recall $^{b}$ & $.25 * *$ & $-\cdots$ & -.02 & $.19^{* *}$ & .06 & .09 & $.25^{* * *}$ & .05 & .01 \\
\hline Recognition ${ }^{b}$ & $.17 *$ & $\cdots$ & -.07 & -.13 & .05 & -.00 & $.15^{*}$ & $.15+$ & .09 \\
\hline $\begin{array}{l}\text { a Cigarette post } \\
\text { b Logistic regre } \\
+ \text { Two-tailed p } \\
\text { * Two-tailed p } \\
\text { ** Two-tailed p } \\
\text { *** Two-tailed p }\end{array}$ & $\begin{array}{l}\text { sure, awa } \\
\text { timates. }\end{array}$ & and belief & & & & & & & \\
\hline
\end{tabular}

that maternal cigarette smoking is harmful to the fetus $(\beta=$ $.17, p<.001)$. Significantly more women believed that maternal alcohol consumption is associated with birth defects $(\beta=-.15, p<.001)$. Subjects exposed to the alcohol warning label were marginally more likely to believe that alcohol consumption can lead to fetal injury $(\beta=.07, p<.10)$.

\section{Beliefs 2}

The only variable that accounts for significant variance in the belief that it is beneficial to avoid alcohol during pregnancy is the corresponding cigarette measure $(\beta=.74, p<$ $.001)$.

\section{Warning Poster Memory}

The law variable accounts for significant variance in accuracy of both free-recall $(\beta=.25, p<.01)$ and recognition $(\beta$ $=.17, p<.05$ ) memory for the warning on the Arizona alcohol warning poster. No comparable cigarette memory question was available because there is no Arizona cigarette warning poster. Age significantly predicts recall $(\beta=.19, p$ $<.01$ ), but not recognition memory. Exposure to the warning poster at work is a significant covariate for both recall and recognition memory $(\beta=.25, p<.001)$, and $(\beta=.15$, $p<.05)$, respectively. Exposure to the alcohol warning label is marginally significant for recognition memory $(\beta=$ $.15, p<.10$ ), but not for recall.

\section{Homogeneity of Regression Slopes}

The test for homogeneity of regression slopes was carried out for two sets of models: (1) a set of equations containing just the independent variable (LAW), the cigarette covariate
(CIG), and their interaction term (LAWXCIG) for each dependent variable and (2) a set of equations containing these terms (LAW, CIG, and LAWXCIG) as well as the main effect and interaction terms of the two most consistently significant covariates-work exposure (WORKALC and the LAWXWRK interaction term) and warning label exposure (LABEL and the LAWXLBL interaction term).

\section{Model Containing Cigarette Covariate Only}

The introduction of the alcohol warning poster is significantly related to reports of exposure to the warning poster $(\beta=.14, p<.001)$. Reports of having seen a cigarette warning poster are also related to alcohol warning poster exposure $(\beta=.36, p<.001)$. The interaction term is not significant $(\beta=.01$, n.s.). Similarly, both warning poster introduction and the cigarette covariates are related significantly to alcohol warning poster awareness $(\beta s=.15, p<.001$, and $\beta$ $=.37, p<.001$, respectively), warning poster law awareness ( $\beta s=.11, p<.01$, and $\beta=.42, p<.001$, respectively), and the beliefs item asking about the relationship between substance use during pregnancy and birth defects $(\beta=.11, p<$ .01 , and $\beta=.19, p<.001$, respectively). Thus, none of these models indicate heterogeneity of regression slopes.

The second beliefs item, however, does reveal a significant interaction term $(\beta=.09, p<.001)$. As in previous analyses, the regression coefficient for the cigarette covariate is highly significant $(\beta=.74, p<.001)$ and the coefficient for the introduction of the alcohol warning poster is nonsignificant. No interaction term was tested in the models for the recognition and recall dependent measures because there was no cigarette covariate to include in these models. 


\section{Model Containing Two Additional Covariates}

The same pattern of results reported in the preceding ANCOVA section is found for the exposure, poster awareness, and law awareness variables: the appearance of the warning poster accounts for significant variance in each dependent variable $(\beta=.15, p<.01, \beta=.18, p<.01$, and $\beta=.12, p<$ .05 , respectively), as do each cigarette covariate $(\beta=.35, p$ $<.001, \beta=.35, p<.001$, and $\beta=.41, p<.001$, respectively), the work exposure variable $(\beta=.14, p<.001, \beta=$ $.12, p<.001$, and $\beta=.15, p<.001$, respectively), and the warning label exposure variable $(\beta=.10, p<.01, \beta=.14$, $p<.001$, and $\beta=.13, p<.001$, respectively). None of the interaction terms are significant.

The model including the beliefs about birth defects dependent variable also has no significant interaction terms, however, their inclusion in the model reduces the law regression coefficient and this term is statistically nonsignificant $(\beta=.04$, n.s.). The cigarette covariate is the only term to reach significance in this model $(\beta=.19, p<.001)$. The model containing the beneficial-to-avoid beliefs dependent variable also yields a significant cigarette covariate $(\beta=$ $.75, p<.001$ ). In contrast to the results of previous models using this dependent variable, the appearance of the warning poster is marginally related to beliefs about whether it is beneficial to avoid drinking during pregnancy $(\beta=.07, p$ $<.10$ ). Though the two remaining covariates do not account for significant variance in this beliefs item, the law by work exposure interaction term is significant, indicating heterogeneity of regression slopes. Work exposure and beliefs were more highly related after the poster appeared, which may account for the now significant law coefficient.

For both recall and recognition memory items, the introduction of the alcohol warning poster remains significantly related to more accurate memory $(\beta=.19, p=.06$, and $\beta=$ $.23, p<.05$, respectively). In the recall model, warning label exposure does not account for significant variance in memory, but exposure to the poster at work does $(\beta=.24, p<$ $.001)$. A significant law by warning label exposure interaction term indicates heterogeneity of regression slopes for the warning label exposure covariate $(\beta=-.19, p<.05)$. Both exposure covariates are related significantly to recognition memory (work exposure $\beta=.14, p<.05$ and label exposure $\beta=.15, p<.05$ ), and neither of the interaction terms is significant.

\section{Discussion}

We used several different outcome measures (e.g., exposure to the poster, beliefs about birth defects) as potential indicators of the short-term effectiveness of the Arizona alcohol warning poster. The pattern of results with these indicators suggests that the warning poster had an immediate effect on a college sample's exposure to the poster, awareness of the poster and the law requiring it, and memory for the warning message on the poster. We find inconsistent evidence for an effect on beliefs about the association between maternal alcohol consumption and birth defects.

\section{Exposure}

Though establishing a link between the introduction of and having seen the warning poster may seem trivial, some re- searchers believe health warnings are rarely even noticed [Myers 1981, cited by McCarthy et al. 1984]. More subjects reported seeing the alcohol warning poster after the legislation. More subjects also reported seeing a cigarette warning poster, which is surprising because a cigarette version of the alcohol warning poster does not exist in Arizona. This finding may reflect subjects' exposure to the cigarette warning poster in the bordering state of California. Another explanation is that what subjects are reporting as exposure to the Arizona cigarette warning poster is actually exposure to the Surgeon General's cigarette warning, which they see on billboards and in various other sources throughout the state. Finally, there may be a general trend to report exposure to all health-related warnings and messages describing drug effects on the fetus. The most parsimonious explanation for these results is that the introduction of the alcohol warning poster led to a change in the exposure dependent measure because significant variance in the exposure dependent variable is accounted for by the law variable, even when the cigarette exposure variable is included as a covariate.

\section{Awareness}

After the law was enacted, more subjects were aware that the alcohol warning poster existed and that it was required in Arizona. As with the exposure dependent variable, awareness of a fictitious cigarette warning poster also increased from wave 1 to wave 2 . Despite the variance accounted for by awareness of a fictitious cigarette warning poster, the introduction of the alcohol warning poster is a statistically significant predictor of awareness.

Other researchers have found a significant interaction between introduction of a warning label and alcohol use such that heavier drinkers have the highest awareness of the label after it appears [Kaskutas and Greenfield 1991; MacKinnon, Pentz, and Stacy 1993; Mazis, Morris, and Swasy 1991]. The interaction of alcohol use and alcohol warning message introduction is not statistically significant in our study. The effects of a warning poster may differ from those of a warning label. The warning poster may have a more subtle effect because it is not, for example, seen directly on the alcohol container during drinking behavior. Perhaps both heavy and light drinkers look at the warning poster briefly upon entering a drinking establishment. If so, the interaction may be present only when heavy drinkers have much greater exposure to the warning poster than light drinkers.

\section{Beliefs}

We find inconsistent evidence for an association between the introduction of the alcohol warning poster and beliefs about the relationship between maternal consumption of alcohol and birth defects. The results from the main effect ANCOVA model suggest an effect of the poster on more accurate beliefs, but the model in which interaction terms are included to test for parallel regression slopes indicates that the effect on beliefs is nonsignificant. Interestingly, none of the interaction terms in that model are significant, indicating homogeneity of regression slopes. This finding suggests that the initial ANCOVA model was an appropriate model to use. 
The lack of association between the introduction of the poster and beliefs about the benefits of avoiding alcohol during pregnancy may be due to a ceiling effect, as the wave 1 mean response to this item was very high.

\section{Memory}

Subjects were better at both recalling the content and recognizing the exact wording of the alcohol warning poster after it appeared.

\section{Summary}

The overall pattern of results suggests immediate effects of the warning poster. The introduction of the Arizona alcohol warning poster is associated with increased exposure to the poster, increased awareness of the poster and the law requiring it, and more accurate memory for the warning message on the poster. Some evidence suggests the introduction of the warning poster is associated with more accurate beliefs about maternal alcohol consumption and birth defects, though analyses with different underlying assumptions yield inconsistent results.

The obtained pattern of results is very similar to findings from alcohol warning label evaluations. Alcohol warning labels, like the alcohol warning poster, are being noticed by the public [MacKinnon, Pentz, and Stacy 1993; Mazis, Morris, and Swasy 1991; Scammon, Mayer, and Smith 1991]. However, as in the case of the alcohol warning poster, the relationship between warning message introduction and perception of risk [Scammon, Mayer, and Smith 1991] and beliefs about birth defects [MacKinnon, Pentz, and Stacy 1993; Mazis, Morris, and Swasy 1991] has not been clearly demonstrated.

Our study has several limitations. First, the effects of the warning poster legislation may be over or underestimated because of the short followup period. The effects of the poster may increase as more people see it and are exposed repeatedly to it. Alternatively, the warning poster may have only immediate effects that dissipate. Furthermore, the media coverage of the alcohol warning poster legislation, rather than the poster itself, may be responsible for some portion of the immediate effects we report. To address this possibility, we analyzed responses to the following questionnaire item: "Where have you seen or heard about the risks of drinking alcohol while pregnant?" Response choices included "newspapers," "magazines," "television," "radio," and "billboards," in addition to "a poster." Significantly more subjects chose the "poster" response after the alcohol warning poster legislation became effective. We find no significant change in any of the other responses. As this question was asked near the beginning of the questionnaire, the wording of other items is not likely to have influenced responding.

A second issue, hinted at in the Exposure subsection, is the high level of reported awareness of and exposure to a nonexistent cigarette warning poster. Though interpretation of results would have been clearer without this finding, it does not invalidate the conclusion that the alcohol warning poster was associated with changes in awareness of and exposure to the Arizona alcohol warning poster. There are plausible explanations for subjects' reports of seeing a cigarette poster (e.g., seeing the poster in California), and for the re- lationships between exposure to and awareness of the alcohol and cigarette warning posters (e.g., health conscious people might report both). However, the introduction of the alcohol warning poster accounts for significant variance in the exposure and awareness dependent measures when adjusted for other variables, including the cigarette covariates.

A third issue is that some subjects in wave 1 , or the baseline measurement point, are likely to have had previous exposure to a similar alcohol warning poster or similar warning message. For example, subjects may have been exposed to a poster in Phoenix or California (or another city or state that already had the poster), or they may have been exposed to the message on the alcohol warning label. Exposure in each of these conditions was measured and included as a covariate in the ANCOVA. If exposure to these other messages had been less, perhaps stronger effects would have been found.

Fourth, because of the questionnaire format, subjects read items that may have influenced how they responded to subsequent items. For example, after responding to the question, "Have you seen posters in Arizona that warn of the harm of a pregnant woman's alcohol consumption to her unborn baby?," subjects were given either a recognition or a free recall memory test for the contents of the poster. Though this ordering may have affected subjects' responses, this problem is probably minimal for two reasons. First, half of the subjects were given a recognition memory test, which had the correct warning and a very similar distractor warning. Previous questions could not have aided responses to the recognition memory test unless they reflected the exact wording of the warning poster, which they did not. Second, both recognition and free-recall memory items became more accurate from wave 1 to wave 2 . As the question ordering was constant across waves, response set is an unlikely explanation for the increase in accuracy of memory.

A final potential criticism of the study is that the best sample for this type of study is a sample of pregnant women. Pregnant women are the group whose behavior ultimately must change if FAS is to be prevented. However, the Arizona alcohol warning poster legislation was created to "educate(s) the general public, and pregnant women in particular" of the risks associated with maternal alcohol consumption [Arizona State Senate Fact Sheet for S.B. 1132 1991, 1]. Thus, the legislation targets both the general public and pregnant women. Our analysis of the immediate, overall effects of the alcohol warning poster is important because it addresses a primary ${ }^{4}$ objective of the Arizona alcohol warning poster legislation.

\section{Implications}

The health, social, and economic costs associated with maternal alcohol consumption make it a topic of immediate national concern [U.S. Department of Health and Human Services 1990]. Alcohol warning posters, if effective, are one relatively low cost strategy for informing the public about the risk. Many researchers believe warnings in general are ineffective-many asserting that this ineffectiveness is more detrimental than the absence of a warning [Driver 1987; Engs 1989]. One rationale for this assertion is that 
the public is so inundated by warnings that truly important warnings may be missed [Driver 1987]. Others believe that an ineffective warning merely creates a protective loophole through which businesses can avoid legal suits [Scammon, Mayer, and Smith 1991]. This concern may be warranted as the distinction between a warning and a disclaimer may be unclear [Weinstein et al. 1978].

The arguments for warnings are also compelling. Warnings provide information that may be used to avert injury at a low cost. Furthermore, preliminary analysis reveals that the purely informational format such as that of the current Arizona alcohol warning poster evokes an almost universally positive response. Other researchers have found that warnings directing behavior (e.g., "You should....") in addition to or instead of providing information may be met with reactance [see Brehm 1966], thus having the opposite of the intended effect on behavior [Bensley and Wu 1991].

Whether warnings are a good or bad idea, evaluations of warnings are needed to determine what, if any, effects they have and how closely these effects are related to the initial goals of the legislation. Our findings suggest the Arizona alcohol warning poster is having immediate and positive effects on exposure, awareness, and memory. Future research targeting pregnant women, and perhaps covering a longer followup period, is needed to address whether the poster will reduce the number of FAS and FAE babies born.

\section{Notes}

1. Though a similar law went into effect for just Phoenix several months earlier (July 1991), our research is on the effects of the state law. Subject reports of residence are included to adjust for persons who lived in Phoenix during the summer of 1991.

2. The exposure variables are (1) working in an establishment that serves alcohol, (2) having lived in a state that has the alcohol warning poster, and (3) exposure to the alcohol warning label.

3. The means are adjusted for gender, age, race, alcohol use, employment in an establishment that serves alcohol, residence the past year in a state that has an alcohol warning poster, and exposure to the alcohol warning label.

4. Though increasing the general public's awareness is mentioned first, it does not indicate priority, but rather the numerical order in which the target populations are mentioned in the legislation.

\section{References}

Abel, Ernest L. and Robert J. Sokol (1986), “Fetal Alcohol Syndrome Is Now Leading Cause of Mental Retardation,' Lancet (November 22), 1222.

Andrews, J. Craig, Richard G. Netemeyer, and Srinivas Durvasula (1990), "Believability and Attitudes Toward Alcohol Warning Label Information: The Role of Persuasive Communications Theory," Journal of Public Policy \& Marketing, 9, 1-15.

Arizona Revised Statutes § 4-261 (1991).

Bensley, Lillian Southwick and Rui Wu (1991), “The Role of Psychological Reactance in Drinking Following Alcohol Prevention Messages," Journal of Applied Social Psychology, 21, $1111-1124$
Brehm, J.W. (1966), A Theory of Psychological Reactance. New York: Academic Press, Inc.

Cook, Thomas D. and Donald T. Campbell (1979), Quasi-Experimentation Design \& Analysis Issues for Field Settings. Chicago: Rand McNally College Publishing Company.

Driver, Russell W. (1987), “A Communication Model for Determining the Appropriateness of On-Product Warnings," IEEE Transactions on Professional Communication, PC-30 (3), 157163.

Engs, R.C. (1989), “Do Warning Labels on Alcoholic Beverages Deter Alcohol Abuse?" Journal of School Health, 59 (3), $116-$ 18.

Halmeski, Erja (1988), “Alcohol Counselling of 85 Pregnant Problem Drinkers: Effect on Drinking and Fetal Outcome," British Journal of Obstetrics and Gynecology, 95, 243-247.

Hayes, Janice W. (1991), personal communication from Substance Abuse Program Coordinator, Office of the City Manager, City of Phoenix, AZ.

Hilton, Michael (1991), "Preliminary Findings of Research on Alcohol Warning Label," report presented to Bureau of Alcohol, Tobacco and Firearms.

H.R. 5409 (1988), 100th Congress 2D Session.

H.R. 5210 or S. 2852 Omnibus Anti-Drug Abuse Act (1988), 100th Congress 2D Session.

Huitema, Bradley E. (1980), The Analysis of Covariance and Alternatives. New York: John Wiley \& Sons.

Jones, Kenneth L. and David W. Smith (1976), "The Fetal Alcohol Syndrome: Clinical Delineation," Annals of the New York Academy of Science, 273, 130-137.

Christy N. Ulleland, and Ann Pytkowitcz Streissguth (1973), "Pattern Malformation in Offspring of Chronic Alcoholic Mothers," Lancet, 1, 1267-1271.

Kaskutas, Lee and Tom Greenfield (1991), "Knowledge of Warning Labels on Alcoholic Beverage Containers," Proceedings of the Human Factors Society 35th Annual Meeting, Vol. 1. Santa Monica, CA: Human Factors Society, 441-445.

Little, Ruth E., Ann Pytkowicz Streissguth, Gay M. Guzinski, Harrison L. Gratwohl, Judy M. Blumhagen, and Catherine E. McIntryre (1983), "Change in Obstetrician Advice Following a TwoYear Community Educational Program on Alcohol Use and Pregnancy,' American Journal of Obstetrics \& Gynecology, 146 (1), 23-28.

MacKinnon, David P., Mary Ann Pentz, and Alan Stacy (1993), "The Alcohol Warning Label and Adolescents: The First Year," American Journal of Public Health, 83 (4), 585-587.

, Katharine Taft, Laurie Bizzell, Liva Nohre, Alan Stacy, and Mary Ann Pentz (1991), "Adolescent Beliefs About Drinking While Pregnant," paper presented at the American Public Health Association 119th Annual Meeting, Atlanta, GA (November).

May, Philip A., Karen J. Hymbaugh, Jon M. Aase, and Jonathan M. Samet (1983), "Epidemiology of Fetal Alcohol Syndrome Among American Indians of the Southwest," Social Biology, 30 (4), 374-387.

Mazis, Micheal B., Louis A. Morris, and John L. Swasy (1991), "An Evaluation of the Alcohol Warning Label: Initial Survey Results," Journal of Public Policy \& Marketing, 10 (1), 229 241. 
McCarthy, Roger L., James P. Finnegan, Susan Krumm-Scott, and Gail E. McCarthy (1984), "Product Information Presentation, User Behavior, and Society," Proceedings of the Human Factors Society 28th Annual Meeting, Vol. 1. Santa Monica, CA: Human Factors Society, 81-85.

Muthen, Bengt O. (1987), LISCOMP. Analysis of Linear Structural Equations With a Comprehensive Measurement Model. User's Guide. Mooresville, IN: Scientific Software, Inc.

and David Kaplan (1985), "A Comparison of Some Methodologies for the Factor Analysis of Non-Normal Likert Variables," British Journal of Mathematical and Statistical Psychology, 38, 171-189.

Prugh, Thomas (1989), Point-of-Purchase Health Warning Notices," Alcohol Health and Research World, 36.

Rosett, Henry L., Eileen M. Ouellette, and Lyn Weiner (1976), "A Pilot Prospective Study of the Fetal Alcohol Syndrome at the Boston City Hospital, Part I: Maternal Drinking," Annals of the New York Academy of Science, 273, 118-122.

, Lyn Weiner, and Kenneth C. Edelin (1983), "Treatment Experience With Pregnant Problem Drinkers," Journal of American Medical Association, 249 (15), 2029-2033.

Roth, Robert A. (1991), "Report to the Legislature," report prepared as public service document for St. Joseph's Hospital and Medical Center, Mesa, AZ.

Russell, Marcia, Gay E. Kang, and Lois Uhteg (1983), “Evaluation of an Educational Program on the Fetal Alcohol Syndrome for Health Professionals,' Journal of Alcohol and Drug Education, 29 (1), 48-61.

Scammon, Debra L., Robert N. Mayer, and Ken R. Smith (1991), "Alcohol Warnings: How Do You Know When You Have Had One Too Many?' Journal of Public Policy \& Marketing, 10 (1), 214-228.

U.S. Department of Health and Human Services (1990), Seventh Special Report to the U.S. Congress on Alcohol and Health. Rockville, MD: National Institute on Alcohol Abuse and Alcoholism.

Warren, Kenneth R. and Richard J. Bast (1988), "Alcohol-Related Birth Defects: An Update," Public Health Reports, 103 (6), 638-642.

Waterson, E. J. and Iain M. Murray-Lyon (1990), "Preventing Alcohol Related Birth Damage: A Review,' Social Science \& Medicine, 30 (3), 349-364.

Weinstein, Alvin S., Aaron D. Twerski, Henry R. Piehler, and William A. Donaher (1978), Products Liability and the Reasonably Safe Product: A Guide for Management, Design, and Marketing. New York: John Wiley \& Sons, Inc.

\section{Appendix Questionnaire Items}

Demographic Information

-Gender

-Age

-Ethnic/racial category

\section{Covariates and Dependent Variables}

-Where do you work now?

- How many alcohol drinks have you had in the last month?

-Where have you seen or heard about the risks of drinking alcohol while pregnant?

-Are there posters in Arizona restaurants, bars and liquor stores that warn of the harm of a pregnant woman's cigarette smoking on her unborn baby?

- Have you seen posters in Arizona restaurants, bars and liquor stores that warn of the harm of a pregnant woman's cigarette smoking on her unborn baby?

- To the best of your knowledge is there an Arizona law requiring posters in Arizona restaurants, bars and liquor stores that warn of the harm of a pregnant woman's cigarette smoking on her unborn baby?

-Are there posters in Arizona restaurants, bars and liquor stores that warn of the harm of a pregnant woman's alcohol consumption on her unborn baby?

- Have you seen posters in Arizona restaurants, bars and liquor stores that warn of the harm of a pregnant woman's alcohol consumption on her unborn baby?

-To the best of your knowledge is there an Arizona law requiring posters in Arizona restaurants, bars and liquor stores that warn of the harm of a pregnant woman's alcohol consumption on her unborn baby?

- To the best of your knowledge, is there a warning on alcohol beverage containers?

-Have you seen warning labels on alcohol beverage cans or bottles?

-To the best of your knowledge, is there a law requiring warning labels on cans and bottles of beer, wine, and liquor?

-Please write the contents of the Arizona Alcohol Warning poster. If you do not believe there are waming posters in Arizona restaurants, bars, and liquor stores, check here $\square$ and do not complete this question.

-Which of the following warnings is written on the Arizona Alcohol Warning Poster?

1. Drinking alcoholic beverages during pregnancy can cause birth defects

2. Drinking distilled spirits, beer, coolers, wine, and other alcoholic beverages during pregnancy can cause birth defects

3. I don't know what warning is written on the Arizona Warning Poster

- How beneficial would it be for a pregnant woman to entirely avoid drinking alcohol during her pregnancy?

- How beneficial would it be for a pregnant woman to entirely avoid smoking cigarettes during her pregnancy?

- Can drinking alcohol during pregnancy cause birth defects?

- If a pregnant woman smokes cigarettes, it may cause injury to the baby? 
Copyright of Journal of Public Policy \& Marketing is the property of American Marketing Association. The copyright in an individual article may be maintained by the author in certain cases. Content may not be copied or emailed to multiple sites or posted to a listserv without the copyright holder's express written permission. However, users may print, download, or email articles for individual use. 